\title{
BEELDBEVORDERING AS 'N PROMOSIESTRATEGIE EN UITVLOEISEL VAN SOSIAAL-VERANTWOORDELIKE HANDELINGE \\ 'N STUDIE IN DIE WYNBEDRYF
}

\author{
J.H. VISSER * \\ I. VAN W. RAUBENHEIMBER * \\ DEPARTEMENT BEDRYFSIELKUNDE \\ UNIVERSITEIT VAN STELLENBOSCH
}

\begin{abstract}
A survey of the literature indicates that certain economic requirements have to be met should business firms make use of image building as a means of promoting their products. Seven hypotheses about the way in which consumers associate firms with their products in the wine industry are formulated and tested on a sample of 220 students. A skewed distribution of the knowledge of the origin of wines is reported. Furthermore, a significantly greater number of students could specify the trademarks of one of the firms, because this firm more explicitly associates with its products. Results indicate a need for reassessing the economic benefits reaped from image building in the wine industry.
\end{abstract}

Met die eerste oogopslag wil dit voorkom asof die doelstellings van die handelswêreld (spesifiek sakeondernemings) onomstrede is. Tradisioneel en histories word 'n sakeonderneming as 'n ekonomiese instansie beskou met 'n fundamentele maatstaf van effektiwiteit, naamlik winsmaksimering, wat algemeen en uniek aan bedryfsvoering is. Dit sou dus wou voorkom asof winsbejag, of die maksimering van wins, die natuurlike enkele sakedoelstelling behoort te wees. In werklikheid is sakedoelstellings een van die mees omstrede onderwerpe van die sake-etiek in die jongste jare. (Ansoff, 1970, p.37)

Winsgewendheid as fundamentele norm van die handelswêreld is hedendaags onderworpe aan skerp kritiek en bevraagtekening. Verskeie skrywers het al gepoog om winsmaksimering as enkele hoofdoelstelling te vervang met byvoorbeeld oorlewing, diens aan die verbruiker of sosiale verantwoordelikhede. Hay, Gray en Gates (1976, p.13) skryf hierdie

\footnotetext{
* Tans by die Randse Afrikaanse Universiteit.
} 
omstredenheid toe aan die groeiende bewuswording van die noodsaaklikheid van sosiale en gemeenskapsverantwoordelikheid as mede-primêre sakedoelstelling.

Die denkwyse van Adam Smith het sedert die publikasie van "Wealth of Nations" in 1776, veral in die Westerse wêreld inslag gevind en indirek aanleiding gegee tot 'n ekonomies-politiese sisteem op grond waarvan sakelui vir bykans 150 jaar die nastreef van individuele eiebelang beskou het as die beste manier om die algemene welsyn te bevorder.

In die 1930's het daar 'n klemverskuiwing plaasgevind vanaf individuele eiebelang na groepsbelang vanweë 'n gevoel wat ontstaan het dat die beklemtoning van individuele eiebelang allesoorheersend en ten koste van die ander betrokkenes by die sakeonderneming was. Sedert die laat 1960 's het ' $n$ toenemende aantal sakemanne 'n nuwe filosofie wat sentreer om gemeenskapsbelang eerder as die belange van diegene wat 'n bydrae tot die sakeonderneming lewer begin aanhang. Volgens hierdie filosofie verwag die gemeenskap dat sakeondernemings 'n ruimer verantwoordelikheid sal aanvaar - 'n verantwoordelikheid wat verder strek as bloot die nastreef van individuele of groepsbelange.

Sommige van die vroeë aanvaarders van hierdie nuwe filosofie het tot die slotsom gekom dat dit nie noodwendig die fundamentele beginsels van sake-doen skend nie, maar dat dit geïnkorporeer kan word in "n waardesisteem wat as verligte eiebelang bekend staan. Ooreenkomstig die beginsels van verligte eiebelang, onderneem sakeondernemings sekere sosiaal-verantwoordelike handelinge (byvoobeeld bevordering van die kuns) met die verwagting dat sodanige projekte wel oor die langtermyn dividende sal afwerp. Hul verwag dat die (duur) positiewe beeld wat oor die langtermyn opgebou word, uiteindelik na die produkte van die sakeonderneming sal oordra deur middel van die gunstige vooraankoop-invloed wat dit op die verbruiker kan uitoefen. Oordrag is egter nie vanselfsprekend nie. Die verbruiker moet onder andere die produkte wat deur daardie sakeonderneming vervaardig word, kan identifiseer; met ander woorde daar moet 'n koppeling tussen 'n sakeonderneming en sy produkte moontlik wees.

By nadere ondersoek blyk dit dat sommige sakeondernemings hulle veral beywer vir byvoorbeeld omgewingsbewaring, sport en die bevordering van die kunste. Aangesien sodanige sosiaal-verantwoordelike projekte in ooreenstemming met die beginsels van verligte-eiebelang is, verwag die betrokke sakeondernemings (of behoort hulle te verwag) dat hulle pogings oor die langtermyn dividende sal afwerp. Die realisme van hierdie verwagtings word egter tans deur ' $n$ bepaalde diskoers (Raubenheimer, 1977) wat soos volg saamgevat kan word, bevraagteken: 
- Aangesien groot sakeondernemings gewoonlik 'n groot verskeidenheid van produkte van verskillende aard, kwaliteit en prys vervaardig en onder individuele handelsmerke bemark, is die vele produketikette vanweë hulle uiteenlopendheid individueel en gesamentlik visueel raserig. Dit is dus vir die verbruiker moeilik om die verskillende name te onthou en dit aan ' $n$ bepaalde sentrale idee (bv. die naam van die sakeonderneming) te koppel.

- In die groot verskeidenheid van produkname is daar dikwels geen oorkoepelende gemeenskaplikheid (sentrale begrip of woord) wat die verbruiker help om die verskillende produkte aan mekaar en aan die sakeonderneming te koppel nie.

- $\quad$ By gebrek aan hierdie informasie kan ' $n$ mens verwag dat relatief min verbruikers die sakeonderneming aan sy produkte sal herken, en dat relatief min verbruikers sal weet watter produkte deur watter sakeonderneming vervaardig word.

- $\quad$ Indien bogenoemde waar sou wees, kan 'n mens verder verwag dat die positiewe beeld wat die sakeonderneming probeer skep nie op (al) sy produkte oordra nie, aangesien daar nie die nodige koppeling of assosiasie tussen sakeonderneming en produk bestaan nie.

In die lig van die voorafgaande argument het dit vir sakeondernemings wat beeldbevordering as ' $n$ promosiestrategie implementeer, noodsaaklik geword om vas te stel of die meeste verbruikers wel kennis dra van die herkoms van produkte wat deur hulle bemark word. ' $n$ Negatiewe aanduiding in hierdie verband sou impliseer dat die fondse wat vir die ondersteuning van sekere gemeenskapsake soos die bevordering van sport en kuns bewillig word, streng gesproke op 'n onproduktiewe en ekonomiese ondoelmatige wyse aangewend word. Die moontlikheid bestaan dus dat geld bestee word waarop daar moontlik geen dividend of rendement is nie. Indien dit nie die geval is nie, behoort fondse wat vir bogenoemde doeleindes bewillig word te lei tot 'n koppeling tussen die beeld van die sakeonderneming en die produk wat dit bemark. Indien die koppeling nie bestaan nie, kan daar 'n vraagteken getrek word oor die rasionaal (ekonomies gesproke) van so 'n promosiestrategie.

Hierdie studie is onderneem met die doel om 'n tentatiewe antwoord op hierdie vraagstuk spesifiek ten opsigte van die situasie in die wynbedryf te kan verskaf. Deur vas te stel of die verbruikers van wyn in staat is om die produsent/bemarker aan sy produkte te herken, kon sekere afleidings aangaande die koppeling tussen sakeondernemings en hulle produkte met 'n groter mate van sekerheid gemaak word. 
In die volgende paragrawe word 'n kort uiteensetting gegee van die strategie en prosedure wat in die studie gevolg is, sowel as die resultate en gevolgtrekkings wat daaruit voortgespruit het.

\section{METODE}

Seker die belangrikste vereiste vir die realisering van die langtermyn ekonomiese voordele wat moontlik uit die toepassing van beeldbevordering as 'n promosiestrategie kan spruit, is die mate waarin die sakeonderneming slaag om oordrag van sy positiewe beeld na sy produkte te bewerkstellig deur middel van 'n koppeling tussen sy naam en sy produkte.

Met inagneming van die moontlike dwaling in die toepassing van die beginsels van verligte eiebelang, kan dit veronderstel word dat daar nie die nodige koppeling tussen sakeondernemings en hulle produkte bestaan nie. Op grond van hierdie veronderstelling is daar besluit om ondersoek in te stel na die mate waarin Blanke studente aan die Universiteit van Stellenbosch die herkoms van wyne kan spesifiseer. Redes vir die keuse van studente as proefpersone word in 'n latere paragraaf aangestip.

\section{Hipoteses}

Die volgende hipoteses is na aanleiding van die reeds gemelde probleemsituasie geformuleer:

$\mathrm{H}_{1}$ : Kennis ten opsigte van die herkoms van wyne onder studente is nie normaal versprei nie.

$\mathrm{H}_{2}$ : Daar bestaan geen beduidende verskil tussen mans- en damestudente ten opsigte van die verspreiding van hulle kennis van die herkoms van wyne nie.

$\mathrm{H}_{3}$ : Daar bestaan geen beduidende verskil tussen senior mans- en damestudente en junior mans- en damestudente ten opsigte van die hoeveelheid kennis van die herkoms van wyne nie.

$\mathrm{H}_{4}$ : Daar bestaan geen beduidende korrelasie tussen inkoopsofistikasie onder studente en hul kennis ten opsigte van die herkoms van wyne nie.

$\mathrm{H}_{5}$ : Daar bestaan geen beduidende verskil in die hoeveelheid kennis ten opsigte van die herkoms van wyne van verskillende maatskappye onder studente nie.

$\mathrm{H}_{6}$ : Daar bestaan geen beduidende verskil tussen junior mans- en damestudente en senior mans- en damestudente ten opsigte van gereeldheid van drankgebruik nie. 
$\mathrm{H}_{7}$ : Daar bestaan geen beduidende verskil onder studente in die frekwensie van keuse van item-alternatiewe ten opsigte van

- drankgebruik

- dranksoort van eerste keuse

- dranksoort van tweede keuse

- $\quad$ inkoopsofistikasie

- $\quad$ kriteria by die aankoop van wyn en

- $\quad$ veronderstelde kennis van herkoms van wyne nie.

\section{Die meetmiddel}

In die ondersoek is gebruik gemaak van 'n vraelys wat spesifiek ontwikkel is om die kennis van verbruikers van wyn ten opsigte van die herkoms van wyne te toets, en om antwoorde te verskaf op die hipoteses wat in die vorige paragraaf geformuleer is.

Aangesien geen sodanige vraelys beskikbaar was nie, moes 'n vraelys ontwikkel word wat die nodige inligting sou kon verskaf ten opsigte van die reeds gemelde hipoteses. Die vraelys is in Afrikaans opgestel en het bestaan uit 15 items, waarvan die eerste sewe items ingesluit is met die doel om inligting te versamel oor die biografiese eienskappe van die proefpersone. Die oorblywende agt items is ingesluit ten einde die nodige inligting te kan versamel vir die bepaling van elke persoon se drankgebruikpatroon, dranksoort van eerste en tweede keuse, mate van inkoopsofistikasie, kontak met persone deur wie voordele met betrekking tot die aankoop van wyn verkry word, kriteria by die aankoop van wyn, asook veronderstelde en werklike kennis van die herkoms van wyne.

Met die uitsondering van drie items wat deur die invul van 'n enkele naam beantwoord kan word, word die items in die meervoudige keusevorm aangebied en beantwoord.

Vir die identifisering van die herkoms van bepaalde produkte (item 15) is 'n lys met die name van 20 bekende handelsmerke wat deur die vier grootste maatskappye in die SuidAfrikaanse wynbedryf gemaak of bemark word, ingesluit. Dit sou dus vir elke student 'n telling uit 20 verskaf wat sy kennis ten opsigte van die herkoms van wyne aandui. Hierdie telling verteenwoordig die totale aantal handelsmerke ten opsigte waarvan die herkoms korrek gespesifiseer kon word. 'n Frekwensietabel vir elk van die vier groepe proefpersone (soos in die monster beskryf) se response op die items van die vraelys is opgestel. Op hierdie wyse kon die aantal persone met 'n bepaalde telling wat dieselfde alternatief by 'n bepaalde item gekies het, bepaal word. 


\section{Die monster}

Die monster het bestaan uit 220 binnemuurse studente aan die Universiteit van Stellenbosch en is saamgestel uit die volgende groepe:

- $\quad 111$ Bedryfsielkunde II studente (68 mans- en 43 damestudente)

- 60 Mansstudente van 'n senior universiteitskoshuis, Majuba.

- $\quad 28$ Arbeidsterapie I damestudente.

- $\quad 21$ Huishoudkunde III damestudente.

Studente met meer as twee jaar akademiese opleiding word as seniors beskou, terwyl juniors bestaan uit eerste- en tweedejaar studente. Die monster het dus uit 81 seniors (21 Huishoudkunde III damestudente plus 60 mansstudente van die koshuis Majuba) en 139 juniors (111 Bedryfsielkunde II studente plus 28 Arbeidsterapie I damestudente) bestaan.

Die volgende aannames en oorwegings maak die gebruik van studente uiters geskik vir die doel van hierdie ondersoek:

- Dit is baie gerieflik om van studente gebruik te maak aangesien groot groepe studente geredelik beskikbaar en bereikbaar is.

- Die studente van Stellenbosch verteenwoordig waarskynlik die meer ingeligte deel van die wynverbruikerspubliek aangesien hulle dikwels direk met wynskoue, wyntoere, asook onthale, kunsuitstallings en -uitvoerings wat deur sakeondernemings in die wynbedryf geborg word, in aanraking kom.

- $\quad$ Studente verteenwoordig gewoonlik die hoër sosio-ekonomiese gedeelte van 'n bevolking en is ook veronderstel om diegene te wees wat in 'n groot mate hulle betrokkenheid by die estetiese waardes (veral die kunste) sal demonstreer. Hierdie tipe student is dan eintlik veronderstel om bewus te wees van die sosiaalverantwoordelike handelinge van sakeondernemings wat hulle beywer vir die bevordering van die kunste.

\section{RESULTATE EN GEVOLGTREKKINGS}

'n Frekwensietabel van tellings behaal ten opsigte van kennis van die herkoms van wyne (item 15) word in Tabel 1 aangetoon. 
Uit Tabel 1 blyk dit duidelik dat die hoogste frekwensie onder beide mans- en damestudente by die lae intervalle voorgekom het. Verdere ontledings van die resultate en gevolgtrekkings is aan die hand van die sewe hipoteses gemaak.

\section{$\underline{\text { TABEL } 1}$}

FREKWENSIETABEL VAN TELLINGS VAN PROEFPERSONE TEN OPSIGTE VAN SPESIFISERING VAN HERKOMS VAN WYNE (ITEM 15)

\begin{tabular}{|c|c|c|c|}
\hline \multirow{2}{*}{ Tellings } & \multicolumn{3}{|c|}{ Frekwensies } \\
\hline & Mans & Dames & Totaal \\
\hline $18-20$ & 0 & 0 & 0 \\
\hline $15-17$ & 1 & 0 & 1 \\
\hline $12-14$ & 5 & 3 & 8 \\
\hline $9-11$ & 14 & 7 & 21 \\
\hline $6-8$ & 32 & 19 & 51 \\
\hline $3-5$ & 34 & 32 & 66 \\
\hline $0-2$ & 42 & 31 & 73 \\
\hline Totaal & 128 & 92 & 220 \\
\hline
\end{tabular}

$\mathrm{H}_{1}$ : Kennis ten opsigte van die herkoms van wyne onder studente is nie normaal versprei nie.

Die Chi-kwadraat metode is gebruik om die data aan 'n normaleverspreiding-pas-toets te onderwerp, en toon aan dat die verkreë verspreiding van kennis beduidend van 'n normale verspreiding van kennis ten opsigte van die herkoms van wyne verskil, $X^{2}(7)=41,54, p<, 001$. Hierdie ontleding toon dus aan dat die nul-hipotese nie hierop verwerp kan word nie, en dat daar aanvaar moet word dat die verkreë data nie-normaal versprei is.

$\mathrm{H}_{2}$ : Daar bestaan geen beduidende verskil tussen mans- en damestudente ten opsigte van die verspreiding van hulle kennis van die herkoms van wyne nie.

Soos voorspel, word die nulhipotese deur die data ondersteun, $X^{2}(5)=3,06, p>, 1$. Daar kan uit die gegewens afgelei word dat geslag nie verband hou met sukses behaal ten opsigte van kennis van die herkoms van wyne nie.

$\mathrm{H}_{3}$ : Daar bestaan geen beduidende verskil tussen seniors en juniors ten opsigte van die hoeveelheid kennis van die herkoms van wyne nie.

'n Ontleding van die resultate dui aan dat die nulhipotese nie verwerp kan word nie, $X^{2}(5)=2,96, p>, 1$. 
$\mathrm{H}_{4}$ : Daar bestaan geen beduidende korrelasie tussen inkoopsofistikasie onder studente en hulle kennis ten opsigte van die herkoms van wyne nie.

Produk-moment korrelasiekoëffisiënt is vir twee groepe proefpersone verkry:

- $\quad$ 'n verband van $r(52)=0,05, p>, 1$ tussen inkoopsofistikasie en kennis van die herkoms van wyne vir die studente wat kontakte in die wynbedryf het deur wie hulle sekere voordele ten opsigte van die aankoop van wyne verkry. Die nulhipotese word dus in hierdie geval ondersteun

- $\quad$ 'n verband van $\mathrm{r}(164)=0,24, \mathrm{p}<, 01$ tussen inkoopsofistikasie en kennis van die herkoms van wyne vir die studente wat geen kontakte in die wynbedryf het deur wie hulle sekere voordele ten opsigte van die aankoop van wyn verkry nie. In hierdie geval moet die nulhipotese verwerp word.

$\mathrm{H}_{5}$ : Daar bestaan geen beduidende verskil in die hoeveelheid kennis van studente ten opsigte van die herkoms van wyne van verskillende maatskappye nie.

'n Ontleding van die data toon aan dat daar geen beduidende verskil in kennis van die herkoms van die wyne van maatskappye 1 en 4 is nie, $t(8)=0,28, p>, 05$. Daar is wel 'n beduidende verskil gevind in die proefpersone se kennis van die herkoms van die wyne van maatskappye 1 en $2, \mathrm{t}(11)=3,47, \mathrm{p}<, 01$, asook dié van maatskappye 2 en 4 , $\mathrm{t}(13)=3,44, \mathrm{p}<, 01$.

Aangesien daar net een produk van maatskappy 3 in item 15 van die vraelys opgeneem is en hierdie produk deur slegs 12 van die 220 proefpersone korrek gespesifiseer kon word, is daar nie enige verdere verwerkings ten opsigte van die betrokke maatskappy se produk gedoen nie. Die nulhipotese word dus in die geval van produkte afkomstig van maatskappye 1 en 4 aanvaar, terwyl dit in die geval van produkte afkomstig van maatskappye 1 en 2, asook 2 en 4, verwerp moet word. Daar kan dus na aanleiding van die resultate behaal in hierdie ondersoek aanvaar word dat beduidend meer studente die handelsmerke van maatskappy 2 korrek kon spesifiseer.

$\mathrm{H}_{6}$ : Daar bestaan geen beduidende verskil tussen juniors en seniors ten opsigte van gereeldheid van drankgebruik nie. Deur middel van die Chi-kwadraat metode is vasgestel dat daar wel ' $\mathrm{n}$ beduidende verskil in die gereeldheid van drankgebruik tussen juniors en seniors bestaan, $X^{2}(4)=8,68 \mathrm{p}<, 1$. 'n Ontleding van die Chi-kwadraatwaarde het aangetoon dat hierdie beduidende verskil toegeskryf kan word aan die feit dat 'n groter persentasie seniors as juniors $(56,8 \%$ teenoor $37,4 \%)$ die kategorie 
"dikwels" gekies het as 'n aanduiding van die gereeldheid waarmee hulle drank gebruik, terwyl 'n kleiner persentasie seniors $(30,9 \%)$ en 'n groter persentasie juniors $(49,7 \%)$ verklaar het dat hulle soms of baie min drank gebruik.

$\mathrm{H}_{7}$ : Daar bestaan geen beduidende verskil onder studente in die frekwensie van keuse van item-alternatiewe ten opsigte van

- drankgebruik

- dranksoort van eerste keuse

- dranksoort van tweede keuse

- $\quad$ inkoopsofistikasie

- $\quad$ kriteria by die aankoop van wyn, en

- $\quad$ veronderstelde kennis van wyn nie.

Beduidende verskille in die keuse van item-alternatiewe is wel ten opsigte van bostaande verkry, en die nulhipotese moet dus hierop verwerp word.

\section{GEVOLGTREKKINGS EN AANBEVELINGS}

Daar is tot die volgende gevolgtrekkings na aanleiding van die verkreë resultate gekom:

- $\quad$ Blanke studente het 'n beduidend skewe (nie-normale) verspreiding van kennis ten opsigte van die herkoms van wyne. Relatief min studente kon die herkoms ten opsigte van 'n verskeidenheid van produkte van verskillende maatskappye korrek spesifiseer, terwyl relatief baie studente geen of 'n baie swak kennis van die herkoms van wyne het.

- Die verwagting is dat bogenoemde gevolgtrekkings ook op sommige ander segmente van die wynmark van toepassing sal wees, aangesien die name van die bekendste en mees gevestigde produkte vir die doel van die ondersoek geselekteer en in die vraelys opgeneem is, en 'n groep proefpersone gebruik is wat veronderstel is om die meer ingeligte verbruikers van wyn te wees.

- Daar bestaan geen beduidende verskil tussen seniors en juniors of tussen mans- en damestudente ten opsigte van hulle kennis van die herkoms van wyne nie.

- Daar bestaan wel 'n beduidende verskil tussen senior- en juniorstudente ten opsigte van gereeldheid van drankgebruik. Daar is gevind dat hierdie beduidende verskil toegeskryf word aan die groter persentasie seniors as juniors wat dikwels drank gebruik, asook die kleiner persentasie seniors en groter persentasie juniors wat soms of baie min drank 
gebruik. Hierdie bevinding behoort met die nodige versigtigheid geïnterpreteer te word, aangesien dit spesifiek betrekking het op die monster wat in hierdie ondersoek gebruik is.

- Daar is 'n aanduiding dat die mate van inkoopsofistikasie wat deur die verbruiker (wat geen voordele met betrekking tot die aankoop van wyn ontvang nie) aan die dag gelê word, verband hou met sy kennis ten opsigte van die herkoms van wyne. Hierdie korrelasie van $\mathrm{r}(164)=0,24$ gee egter nie 'n aanduiding van enige oorsaak-gevolg verhouding nie, en het vanweë sy grootte weinig voorspellingswaarde (slegs 5,9\% van die variansie in inkoopsofistikasie kan geassosieer word met 'n variansie in kennis van die herkoms van wyne). Die aanduiding dat daar nie 'n beduidende verband tussen inkoopsofistikasie (soos gemeet deur die inligtingsvraelys) en kennis van die herkoms van wyne vir diegene wat voordele met betrekking tot die aankoop van wyn verkry, bestaan nie, kan verklaar word op grond van hierdie persone se moontlik gespesialiseerde kennis van die produkte van daardie vervaardiger by wie hulle die voordele ontvang.

- Die herkoms van wyne van verskillende maatskappye is nie in dieselfde mate by die verbruikers bekend nie, moontlik as gevolg van die verskillende mate waarin vervaardigers 'n koppeling tussen hulle naam en hulle produkte moontlik maak (bv. deur middel van reklame). Kennis van die herkoms van wyne hang dus nie slegs af van die bekendheid van 'n produk nie, maar ook van die vervaardiger of bemarker se beleid ten opsigte van 'n koppeling tussen sy naam (en beeld) en sy produkte.

- $\quad$ Gegewe dat die studente se relatief swak kennis van die herkoms van wyne, asook die feit dat 57,3\% van die studente sê dat hulle dikwels, baie of gereeld drank gebruik, $65,5 \%$ van die studente natuurlike wyn as eerste en 23,6\% as tweede keuse selekteer het en $26,4 \%$ van die studente nie in die herkoms van wyne belangstel of meen dat dit nie op die etikette verskyn nie, kan dit daarop dui dat 'n koppeling tussen die maatskappye en hul produkte nie altyd moontlik is nie.

- $\quad$ Kwaliteit en ekonomie is in onderskeidelik 66,4 \% en $25 \%$ van die gevalle as die belangrikste kriterium by die aankoop van wyn gekies, terwyl slegs 1,4 \% herkoms as die belangrikste kriterium gespesifiseer het. Dit blyk dus asof verbruikers baie meer op die produk en sy eienskappe as op die herkoms daarvan ingestel is.

- $\quad$ Alles in ag genome, wil dit uit die resultate van hierdie ondersoek blyk asof daar ten opsigte van maatskappye in die wynbedryf 'n swak koppeling is tussen die maatskappye 
se name en die produkte wat deur hulle vervaardig of bemark word. Alhoewel sommige maatskappye verkies dat hulle produkte nie aan die maatskappy se naam gekoppel word nie, verwag hulle tog dat die positiewe publisiteit wat aan hulle sosiaal-verantwoordelike handelinge of ander maatskappy aangeleenthede verleen word, wel na hulle produkte sal oordra.

In die lig van die verkreë resultate blyk dit egter asof die positiewe beelde wat die sakeondernemings probeer skep nie op (al) hulle produkte kan oordra nie, en moet die ekonomiese doelmatigheid van die wyse waarop fondse aangewend word om hierdie beelde te bevorder, bevraagteken word. Dit blyk dus asof sakeondernemings 'n herwaardering van hulle beleid ten opsigte van beeldbevordering deur middel van sosiaal-verantwoordelike handelinge sal moet maak, aangesien winsgewendheid en die produktiewe aanwending van maatskappy-fondse steeds een van die primêre beginsels van bedryfsvoering is.

$\mathrm{Na}$ aanleiding van die bestaande literatuur op die gebied, sowel as die resultate wat in hierdie ondersoek verkry is, word die volgende aanbevelings aan die hand gedoen:

- $\quad$ In hierdie ondersoek is daar baie klem gelê op die noodsaaklikheid van 'n koppeling tussen 'n sakeonderneming en sy produkte ten einde oordrag van die sakeonderneming se goeie beeld na sy produkte te verseker. Daar is egter kortliks verwys na die dilemma waarin sakeondernemings in die wynbedryf verkeer ten opsigte van die gebruik van 'n individuele in plaas van 'n oorkoepelende handelsmerk - hoofsaaklik as gevolg van die diversiteit van produkte in terme van beide aard en kwaliteit. Dit sal wenslik wees om ondersoek in te stel na die moontlikheid van die gebruik van individuele handelsmerke in terme van die potensiële voordeel wat dit oor die langtermyn vir die sakeonderneming kan inhou. Daar kan verder ook vasgestel word in watter mate die bestaande produkname in die wynhandel verwarrend is in die sin dat dit die verbruikers se retensievermoë benadeel en moontlik die verkope van die produkte beïnvloed. Dit sou ook nuttig wees om vas te stel of die verbruikers van wyn 'n kernnaam verkies om hulle aankope van wyn te vergemaklik, asook aan watter eienskappe so 'n geskikte produknaam sou moet voldoen.

- Daar is tans 'n gebrek aan meetinstrumente vir die bepaling van die geslaagdheid van sosiaal-verantwoordelike handelinge. Aangesien beeldbevordering 'n belangrike onderdeel van enige sakeonderneming se promosiestrategie behoort uit te maak, het dit 
noodsaaklik geword om 'n geskikte metode te vind waarvolgens beeldbevordering deur middel van sosiale projekte - geëvalueer kan word.

\section{OPSOMMING}

'n Oorsig van die literatuur dui daarop dat sakeondernemings wat van beeldbevordering as ' $n$ promosiestrategie gebruik maak, sekere vereistes moet nakom ten einde die potensiële ekonomiese voordele te kan realiseer. Sewe hipoteses oor die koppeling tussen maatskappy en produk in terme van verbruikers se hoeveelheid kennis ten opsigte van die herkoms van wynprodukte, is geformuleer en getoets. 'n Monster van 220 studente is in die ondersoek gebruik en daar is gevind dat kennis ten opsigte van die herkoms van wyne nie-normaal versprei is. Beduidend meer studente kon die handelsmerke van een van die maatskappye korrek spesifiseer, aangesien hierdie maatskappy 'n koppeling tussen sy naam en produkte in 'n groter mate moontlik maak. Die verkreë resultate dui op die noodsaaklikheid van ' $n$ herwaardering van die realiseerbaarheid van ekonomiese voordele van beeldbevordering deur middel van sosiaal-verantwoordelike handelinge.

\section{VERWYSINGS}

Ansoff, H.I. Corporate Strategy. Middlesex: Penguin, 1970.

Hay, R.D., Gray, E.R. \& Gates, J.E. (Reds.) Business and Society. Cincinnati: South-Western Publishing Co., 1976

Raubenheimer, I. van W. Enkele gedagtes oor promosie-strategie in die wynbedryf. Universiteit van Stellenbosch. Ongepubliseerde geskrif, November, 1977.

Visser, J.H. 'n Bedryfsielkundige ondersoek na beeldbevordering as 'n promosiestrategie en uitvloeisel van sosiaal-verantwoordelike handelinge - 'n studie in die wynbedryf. Universiteit van Stellenbosch. Ongepubliseerde M.Comm.-tesis, 1978. 